\title{
COMBINED IRIS RETRACTOR AND LENS EXPRESSOR*
}

BY

\author{
H. B. STALLARD \\ London
}

To achieve upward retraction of the iris when applying forceps to the upper part of the lens capsule for intracapsular cataract extraction Verhoeff used a lip on one blade of the forceps.

The instrument shown in Fig. 1 so retracts the iris that a better view is obtained of the upper part of the lens capsule for application of Arruga's capsule forceps than is possible when using Verhoeff's lipped forceps; moreover, this instrument gives some protection to the iris as well as exposing a fair area of the capsule when a cryoextractor is used.

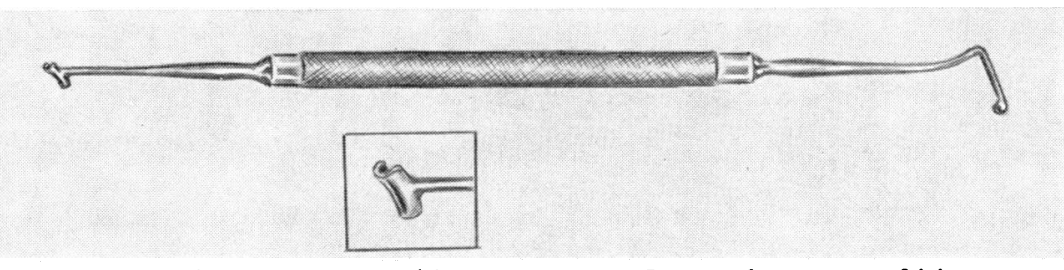

FIG. 1.-Combined iris retractor and lens expressor. Inset, enlargement of iris retractor.

The blade of the iris retractor is $3 \mathrm{~mm}$. long, $0.5 \mathrm{~mm}$. in thickness, curved to conform with the pupil margin, its rolled surfaces are $1 \mathrm{~mm}$. apart, and its free edge extends $1 \mathrm{~mm}$. around the pupil margin on to the posterior surface of the iris. Its edges and corners are rounded so as not to damage either the iris or the lens capsule. The retractor blade is set at an angle of $45^{\circ}$ with the shaft of the round knurled handle for a surgeon who will use it in his left hand and hold the capsule forceps in the right.

Fig. 2 shows the cornea lifted by an assistant through the two arms of a "bridle" corneo-scleral suture to expose the iris and upper part of the lens capsule. The lip of

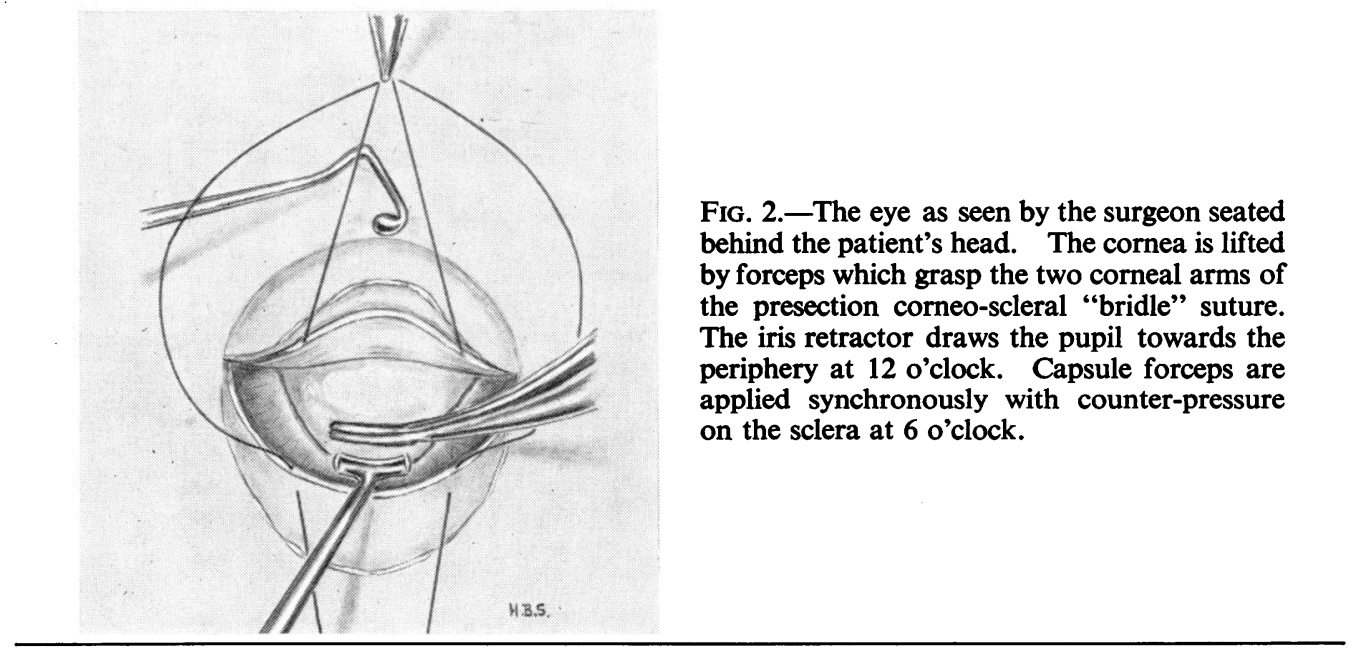

* Received for publication June 21, 1965. 
the iris retractor is slid over the pupil margin and is drawn up. Immediately before application of Arruga's capsule forceps an assistant depresses the sclera with the tip of a lens expressor applied just behind the limbus at 6 o'clock, a manoeuvre which steadies the lens and affords slight counterpressure when the lens capsule is gripped. At the other end of this instrument is Kirby's lens expressor set at about $135^{\circ}$ with the shaft. Immediately the upper part of the lens capsule has been gripped the iris retractor is easily and quickly disengaged. By rotating the shaft and crossing the forefinger over the shaft, the tip of the lens-expressor end is brought into position just in front of the limbus at 6 o'clock.

In principle combined instruments are a hazard in an operation which requires non-touch technique by a surgeon who does not wear gloves. This instrument (Fig. 1) is so held in the middle of the shaft between the surgeon's thumb, index, and second fingers that neither end touches his hand, either on application to the iris of the retractor or in turning over the instrument to apply the expressor.

I thank Messrs. Down Bros. and Mayer and Phelps who made this instrument for me.

\section{MY FAVOURITE EYE MAN}

[The following article is one of a series of personal contributions by advisers, technicians, and administrators who have worked in the developing countries during the past fifteen years under international programmes of technical assistance. Additional information on the overall aid programme is appended.]

I have been tramping for years with my team up and down the dry river valleys that border on the Sahara, seeing that those with enough understanding of trachoma follow simple directions and squeeze soothing ointment, used to treat the disease, into children's eyes. Anti-trachoma work at the field level requires, above all, persistence, a sound supply line, and simple health education. With those three things, the disease can be defeated.

I have been doing field medical jobs for twenty-three years as an adjoint technique de santé, in effect, a public health assistant. I am typical of the many thousands of men, who, after a few years' service in an army medical corps in Africa or Asia, decided that they liked field medicine and went into public health. My credentials consist of a simple nursing diploma and, more important, what I have learned while riding mules, bicycles, camels, and in jeeps to put into practical effect the plans laid down by successive medical officers who have come to this region of the world.

In recent years, some of these medical officers have been sent to southern Morocco by the World Health Organization as part of the U.N. family's world-wide technical assistance programme. They have come at my Government's request to help my colleagues and myself to overcome one of my country's most tragic and avoidable health afflictions-trachoma. 